\title{
Artículos
}

\section{La expansión imperial española en Centroamérica*}

\author{
Rodolfo Cardenal
}

\section{Resumen}

\begin{abstract}
La realidad histórica de la conquista y de la colonia centroamericana muestra que no hubo encuentro de dos mundos ni de culturas, sino, precisamente, una conquista y una colonia que obedecian a unos intereses imperiales. La explotación y la dominación imperial no pueden ser celebradas, tampoco la expansión (o descubrimiento) que les dio origen. La historia desacredita de manera contundente a quienes sostienen la tesis del encuentro y a quienes se apoyan en ella para celebrar ese acontecimiento.
\end{abstract}

Ante quienes se han empeñado en considerar y celebrar los quinientos años del descubrimiento de América como el "encuentro" de dos mundos, culturas o pueblos, se impone la tarea de echar una mirada a la historia para desautorizar esa tesis tan de moda en los medios oficiales, diplomáticos y sociales. La realidad histórica es la única que puede autorizar la tesis del encuentro de los mundos y las culturas. En caso, contrario, afimar que hace quinientos años se encontraron dos mundos y dos culturas es contribuir al encubrimiento y caer en la propaganda ideologizada. Por eso mismo se impone una mirada histórica a la expansión imperial de España en Centroamérica y sobre todo en El Salvador.

Hay que sospechar desde el principio de la ver- dad de la tesis del encuentro, puesto que quienes la sostienen y la celebran caen en una primera contradicción notable. Al mismo tiempo que hablan de encuentro, enaltecen y se enorgullecen de la valentía y la combatividad de Atlacatl y Atonal frente a los conquistadores. Si ambos guerreros prehispánicos lucharon con todas sus energías contra los invasores, entonces, cómo se puede afirmar que hubo encuentro. En cualquier caso, el encuentro fue sumamente violento.

\section{La violencia de la conquista}

Desde los albores del descubrimiento, el enriquecimiento rápido $\mathrm{y}$, concretamente, el oro, obsesionó a los descubridores, invasores y conquista-

* Intervención en la Cátedra Universitaria de Realidad Nacional, el 9 de octubre de 1992. 


\section{Para conquistar los reinos y señoríos de Cuzcatlán fueron necesarias tres expediciones y, aun así, hubo revueltas.}

dores. Colón lo expresó muy bien, en una carta a los reyes, "el oro es el más precioso de todos los bienes, el oro constituye un tesoro, aquel que lo posee tiene todo lo que necesita en este mundo, así como los medios para salvar las almas del purgatorio y enviarlas al gozo del paraíso". Estas líneas sintetizan con exactitud la mentalidad de Colón y de quienes lo siguieron.

La banda de conquistadores dirigida por Pedro de Alvarado, uno de los hombres de Hernán Cortés, salió del altiplano mexicano dirigiéndose hacia el sur, por Soconusco. Envió mensajeros a Iximché (Patinamit), la capital cakchiquel, y su rey aceptó una alianza con los invasores. Más aún, los mensajeros de Alvarado fueron acompañados por muchos esclavos del rey cakchiquel, quienes llevaban presentes por un valor de veinte mil pesos. Deslumbrado por estas muestras de buena voluntad, Alvarado regresó a México. Los cakchiqueles esperaban que Alvarado los ayudara contra sus tradicionales enemigos quichés, tzutujiles y pipiles.

En diciembre de 1523, Alvarado salió de México hacia el altiplano guatemalteco con el propósito de impedir que los enviados de Pedrarias Dávila se apoderaran de Honduras la cual, era considerada como un premio superior por los conquistadores, quienes creían que en sus ríos había mucho oro. Alvarado llegó al altiplano guatemalteco en 1524 con unos trescientos soldados aproximadamente, 135 de ellos a caballo, y con un contingente de guerreros mexicanos, que le servía como tropa de choque. Durante su viaje hacia el sur, algunos de los reinos del altiplano se aliaron con los de Soconusco para hacerle resistencia. En consecuencia, Alvarado tuvo que tomar Soconusco por la fuerza y a muchos de los prisioneros los hizo esclavos de guerra. Alvarado siguió hacia el sur, hacia Sapotitlán (Suchitepéquez) con el objeto de asegurar la región costera.

Al llegar al altiplano guatemalteco, Alvarado encontró a los reinos en guerra entre sí. En ese momento, los dos más poderosos, el de los quichés y el de los cakchiqueles, libraban una guerra. Los últimos habían sido diezmados por varias epidemias devastadoreas entre 1520 y 1521 , cuando se produjo el primier contacto. Los tzutujiles se habían separado y tenían su centro en Atitlán. Una buscada alianza entre los tres reinos frente al invasor fracasó y, en consecuencia, cada uno debió enfrentarlo por su cuenta.

El primer encuentro bélico importante tuvo lugar en el valle de Quezaltenango, donde los conquistadores enfrentaron a los ejércitos quichés, dirigidos por el gran capitán Tecún. Según la tradición, los conquistadores derrotaron sucesivamente a ejércitos de cinco, tres y diez a treinta mil guerreros cada uno. El campo donde los indígenas presentaron la batalla no les favoreció, pues al ser extremadamente plano, los caballos de los conquistadores les permitieron hacer estragos con facilidad en las filas de aquéllos.

Los sobrevivientes se retiraron a su capital Utlatán, la cual por su situación, les parecía inexpugnable. Alvarado fue invitado a ella con muestras de paz y amistad, pero la verdadera intención de los quichés era atraparlo dentro. Alvarado descubrió el engaño, se apoderó de la ciudad con facilidad y quemó vivos a dos de los señores del reino quiché e hizo lo mismo con una parte de la capital. Los del común fueron esclavizados y la quinta parte del rey se pagó con el dinero producido por su venta. Alvarado justificó estos hechos alegando "el bien y el beneficio de este país".

Entonces, el rey cakchiquel envió embajadores de amistad a Alvarado con lo que éste consiguió aliados seguros y una base para operar en el altiplano. Alvarado y sus hombres se dirigieron hacia Iximché, la capital de los cakchiqueles, donde fueron recibidos con temor y respeto. Desde ahí marcharon sobre los tzutujiles, cuyo rey permanecía desafiante. Los mensajeros de Alvarado fueron asesinados en dos ocasiones. Aunque los tzutujiles ofrecieron resistencia, fueron sometidos militarmente al ser derrotados en una batalla, en la ribera del lago Atitlán. Alvarado regresó a Iximché, don- 
de sus relaciones con el rey cakchiquel se deterioraron rápidamente, porque aquél pretendía a una mujer noble esposa del rey. Alvarado capturó al rey y tomó a la mujer. El rey fue liberado después de pagar un rescate en esclavos y joyas.

En sus cartas de relación a Hernán Cortés, Alvarado expresa claramente, en varias oportunidades y en formas distintas, que la población después de haber sido derrotada militarmente, rehuía a los conquistadores, alejándose y sustrayéndose al control efectivo de los nuevos señores. Refiriéndose a los quichés, dice que tuvo que perseguirlos y quemarles las tierras. En esta operación, agrega, ayudaron los cakchiqueles, "e viendo el daño que se les hacía me enviaron sus mensajeros haciéndome saber cómo ya querían ser buenos... y les mandé que se viniesen a sus casas y poblasen la tierra como antes, los cuales lo han hecho así y los tengo al presente en el estado en que antes solían estar, en servicio de su majestad". Esta última afirmación quería decir que la población ya estaba tributando. La cantidad de tributo que debían entregar los sometidos fue tasada arbitrariamente por los conquistadores.

El siguiente paso fue la toma de Yzquintepeque (Escuintla), el centro de los pipiles, cuya capital (Panatacat) fue atacada durante la noche. Sin embargo, el sometimiento rápido de la población impidió a los conquistadores hacer muchos esclavos. En una de sus cartas de relación, Alvarado relata esta conquista en los términos siguientes, "se metieron por los montes que no tuve lugar de les hacer daño ninguno, más de quemarles el pueblo. $Y$ luego les hice mensajeros a los señores, diciéndoles que viniesen a dar obediencia a sus majestades, y a mí en su nombre, y si no que les haría mucho daño en la tierra y les talaría sus maizales. Los cuales vinieron y se dieron por vasallos de su majestad".

Alvarado siguió hacia el sur y llegó a Atiquipaque, donde la población, después de una amistosa bienvenida inicial, huyó a los montes. La de Nacendalán (Nacintla) rehusó someterse y atacó la retaguardia de Alvarado, matando a muchos auxiliares y apoderándose de las provisiones. Entonces, Alvarado incendió la ciudad y quemó vivos a algunos nobles. La gente de Pasaco se pre-

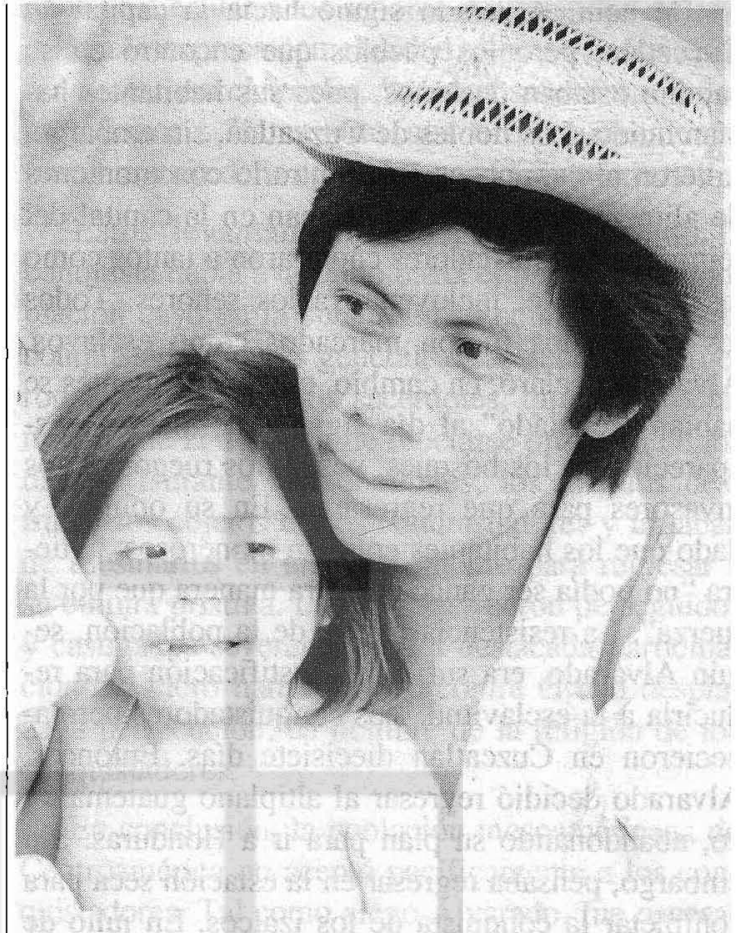

sentó en plan de guerra. Los sirvientes nativos huyeron, llevándose las provisiones de los conquistadores. Esto úllimo ocurría con frecuencia e incitaba la ira de Alvarado, pues el grupo dependía de la población para alimentarse. Los de Pasaco atacaron e hirieron a Alvarado y mataron su caballo y los de otros conquistadores. La población los puso en ridículo y desafió su paciencia. Además, rehusó proporcionarles alimentos y los engañó varias veces, diciéndoles que iba en son de paz, pero después los atacaba. Este desprecio a lar armas españolas fue tomado como un insulto que debía ser vengado "por el bien de la tierra".

Finalmente, Alvarado y su banda cruzaron el río Paz y se dirigieron hacia Cuzcatlán, pero se encontraron que la población huía ante su avance. Frustrado por estas "deserciones", Alvarado mandó capturar a tantos como fuera posible para marcarlos como esclavos. Así, hizo esclavos en los pueblos de Moquizalco y Acatepeque. Cerca de Acajutla lo esperó un gran ejército que fue derrotado. En la batalla, Alvarado fue herido en una pierna por una flecha que lo clavó a la montura. Días después sometió a una fuerza mayor en el pueblo de Tacuxcalco. 
De aquí, Alvarado siguió hacia la capital de Cuzcatlán, pero los pueblos que encontró en su camino estaban desiertos, pues sus habitantes habían huido. Los nobles de Cuzcatlán, sin embargo, salieron al camino para encontrarlo con montones de alimentos. Cuando ya estaban en la capital del reino, los conquistadores capturaron a tantos como les fue posible, incluyendo a los señores. Todos los capturados fueron marcados como esclavos. Alvarado declaró, en cambio, que los habitantes se habían "rebelado" al día siguiente y habían desaparecido en los bosques, pese a los ruegos de los invasores para que regresaran. En su opinión y dado que los habitantes eran tan numerosos, la tierra "no podía ser ganada de otra manera que por la fuerza". La resistencia pasiva de la población, según Alvarado, era suficiente justificación para reducirla a la esclavitud. Los conquistadores permanecieron en Cuzcatlán diecisiete días. Entonces, Alvarado decidió regresar al altiplano guatemalteco, abandonando su plan para ir a Honduras. Sin embargo, pensaba regresar en la estación seca para completar la conquista de los izalcos. En julio de 1524, Alvarado y su banda de conquistadores se establecieron en Iximché. Más tarde, se trasladaron a Ciudad Vieja.

En 1525, Alvarado envió otra expedición a Cuzcatlán, probablemente al mando de uno de sus cinco hermanos o de uno de sus primos. No hay informe algunos sobre esta expedición. En 1526, Pedro de Alvarado atendió el llamado de Cortés desde Honduras y atravesó el territorio salvadoreño sin encontrar oposición alguna hasta Choluteca. Pero, a su regreso, encontró a la población alzada en armas y tuvo que luchar en varias ocasiones. Esta resistencia en territorio salvadoreño estaba alentada por la rebelión de los cakchiqueles, en el altiplano de Guatemala, en 1526. Ello obligó a que todos los conquistadores se retiraran de San Salvador y se concentraran en Guatemala.

La tercera y última tentativa exitosa para conquistar Cuzcatlán desde Guatemala ocurrió en los primeros meses de 1528. Después de la derrota militar de la población nativa, los vencedores se repartieron el territorio y su población. Aparentemente, éstos establecieron su base de operaciones en San Salvador, desde donde incursionaron los territorios vecinos. Lo mismo ocurrió en la provincia de Chaparrastique, donde la base de operaciones estaba en San Miguel.

El patrón de resistencia de los pipiles y lencas fue similar, caían súbitamente sobre los asentamientos de los conquistadores y sus aliados. A veces, se levantaba toda una región en un ataque concertado y sorpresivo. Esto fue lo que sucedió en 1528, en San Salvador, y en 1537, en San Miguel. Al ser repelidos, los pipiles y los lencas se retiraban a sus fortificaciones en los cerros, desde las cuales se defendian contra sus perseguidores arrojando flechas y rodando piedras. Después de atacar San Salvador en 1528, los pipiles se retiraron a Cinacantlán, a donde fueron seguidos y sitiados por los primeros pobladores de aquel asentamiento. Al principio, los pipiles mantuvieron alejados a los conquistadores con sus flechas, pero éstos se acercaron protegidos por una torre móvil de madera y les dispararon desde una altura similar. Asustados, los pipiles propusieron conversaciones de paz y permitieron la entrada en el recinto de varios conquistadores, quienes subirían desarmados para negociar la tregua. Pero estos subieron armados y al entrar en la fortaleza, atacaron a los pipiles, junto con sus compañeros. De este modo, la victoria fue conseguida con engaño. Los conquistadores alegaron después que los pipiles estaban tramando una traición para matarlos.

Aparentemente, la población de estos reinos carecía de la coordinación necesaria para sostener una verdadera guerra de guerrillas; tampoco hubo una política de hostigamiento continuo, aunque existe la leyenda de Atlacatl, quien supuestamente dirigió una resistencia ininterrumpida desde las montañas, durante ocho años. Como quiera que haya sido, parece que las amenazas de severas represalias punitivas mantuvieron a la población dócil la mayor parte del tiempo, lo que permitió a los conquistadores consolidar sus posiciones rápidamente, después de 1528, hasta 1537-1539, cuando ocurrió la revuelta de Higüeras. Esta rebelión la dirigió el cacique Lempira y su centro estuvo en Higüeras (Honduras) pero, por medio de una alianza, en ella participaron los lencas de la región de Chaparrastique. La rebelión obligó a los conquistadores a replegarse a la ciudad de San Mi- 
guel, de donde también estuvo a punto de expulsarlos.

Fuera de los centros urbanos, donde la organización social era más débil, los conquistadores encontraron resistencia militar durante muchos años. La resistencia a la conquista persistió más en las áreas donde las formas de organización social estaban menos desarrolladas, puesto que era difícil encontrar a la población fija en un sitio determinado. En cambio, resultó más fácil conquistar las poblaciones sedentarias con un centro urbano establecido. Tomado el centro, todo lo demás caía en sus manos simultáneamente. Las conquistas de la década de 1520 . no fueron más que el comienzo, pues todavía no habían derrotado a los tzendales y tzotziles de Chiapas; los mames, pocomames, ixiles y kekchíes de Guatemala; los lencas de la costa del Pacífico de Guatemala y El Salvador, para no mencionar los muchos señoríos pequeños y a los todavía más numerosos cacicazgos dispersos en el área mesoamericana de Centroamérica. Uno de los señoríos más difícil de someter fue el de los mames del área de Huehuetenango. Bajo las órdenes de su señor, Caibil Balam, los mames se atrincheraron en el antiguo centro fortificado de Zaculeu, donde resistieron durante cuatro meses las embestidas de ciento veinte soldados y de dos mil guerreros mexicanos y quichés. Cuando la fortificación fue tomada, los vencedores encontraron unos 1,800 mames muertos, la mayor parte de ellos por hambre.

Después de la conquista del altiplano guatemalteco, los conquistadores continuaron ocupados enfrentando revueltas sucesivas, consecuencia de los pesados tributos y trabajos forzados que impusieron sobre la población. Entre esas revueltas están las rebeliones de los quichés y cakchiqueles, en Guatemala, y los mayas, en Yucatán. En 1526, el altiplano guatemalteco y Cuzcatlán ardían en las llamas de la rebelión y los conquistadores estuvieron a punto de ser derrotados. Sin embargo, algunos de los reinos, incluyendo a los tuztujiles y quezaltecos, permanecieron leales $\mathrm{y}$, de este modo, los invasores pudieron sofocar la rebelión. La sublevación de los cakchiqueles que duró cuatro años comenzó cuando Alvarado les exigió que le entregaran, en cinco días, 1,500 pesos en oro, so pena de ejecutar a los señores. La finalidad de esta guerra la expresa con claridad el autor de los Anales de los cakchiqueles, "no nos sometimos a los castellanos... La muerte nos hirió nuevamente, pero ninguno de los pueblos pagó tributo...".

Estos levantamientos ocurrieron cuando la conquista había avanzado hasta el punto que la población cayó en la cuenta de su condición real de conquistada. Por lo general, estas rebeliones fueron instigadas por los sacerdotes, quienes proclamaron que la decisión de rebelarse provenía de los dioses. Durante las rebeliones, los alzados destruían los objetos de los conquistadores y trataban de asesinarlos en un vano intento para regresar a su cultura prístina. Los señores fueron perseguidos y castigados severamente. La destacada participación del clero nativo desató contra él una despiadada persecución, en nombre de la religión de los conquistadores.

En conclusión, la población mesoamericana de Centroamérica no aceptó pacíficamente a los conquistadores. Tal como alegó Alvarado, fue necesario tomar la tierra por la fuerza, porque sus habitantes eran muchos. Para conquistar los reinos y señoríos de Cuzcatlán fueron necesarias tres expediciones y, aun así, hubo revueltas. La resistencia a la conquista se prolongó durante dos décadas, hasta 1540 . Pese a las primeras derrotas militares, la población no se resignó a estar sometida y se levantó en armas en 1526, 1528 y 1537.

La población usó todos los recursos disponibles para evitar la conquista, la esclavitud y el tributo. Huyó ante el avance de los conquistadores, dejando desiertos sus poblados, les tendió trampas y emboscadas, asesinó a sus embajadores, los engañó, les negó y les robó los alimentos, los hostigó y les quitó la paciencia. El conquistador interpretó todo esto como "deserción", lo cual justificaba el terror y la esclavitud. Sin embargo, no hubo unanimidad, pues algunos reinos y señores se aliaron con el conquistador tratando, en vano, de obtener ventajas sobre sus antiguos rivales. Estas divisiones fueron muy importantes para decidir la conquista. Pero los conquistadores ni siquiera respetaron a sus propios aliados a quienes traicionaron, capturándolos, asesinándolos, esclavizándolos y robándolos. 
Cuando Alvarado fue acusado de crueldad en el juicio que se le siguió en México, no refutó el cargo, pero se defendió echando en cara al rey que las crueldades habían redundado en gran beneficio para la corona, "todas las guerras y castigos que se han fecho han sido cabsa que la tierra esté como está debajo de dominio e servidumbre, e sy no se hiziera, segund la multitud de yndios e los pocos cristianos que avía, no se ganara, de que Vuestra Majestad no fuese servido".

\section{La falsa paz colonial}

La historia colonial está determinada por el intento de los conquistadores y de los primeros pobladores y sus descendientes de enriquecerse rápidamente y de convertirse en señores de los territorios y de la población conquistados. Para ellos se trataba de recibir y gozar de las recompensas prometidas y de llevar a cabo su ideal político.

Siempre quisieron enriquecerse rápidamente para regresar a la península ricos y con prestigio. Estaban ansiosos por encontrar la llave mágica que les llevara a la riqueza. Por eso, la conquista de Centroamérica tuvo más de saqueo que de ocupación militar. La búsqueda de la riqueza fue desesperada y exitosa hasta cierto punto. Estas ambiciones hicieron que, durante las dos primeras décadas, es decir, entre 1520 y 1540 , la esclavización de la población conquistada y la explotación de los metales preciosos (el oro y la plata), más que la posesión de la tierra, adquirieran suma importancia. De esta forma, el tráfico de esclavos indígenas y la acumulación de oro y plata se convirtieron en oportunidades para enriquecerse.

Cuando los conquistadores se convirtieron en colonizadores, en la segunda mitad del siglo XVI y a comienzos del siglo XVII, y cuando las dos primeras actividades —el tráfico de esclavos nativos y la explotación de los metales preciosos- no dieron los resultados esperados, se concentraron en el monocultivo. La ambición siguió siendo la misma. En los dos siglos posteriores a la conquista siguieron buscando una clave sencilla que satisfaciera su enorme ambición. La concentración en un sólo producto no fue absoluta, pero llevó a los colonizadores a abandonar o, al menos, a negar otras actividades. Durante la colonia, la actividad agrícola experimentó diferentes estados de productividad y decadencia, dependiendo de cuál de ellas rindiera más beneficios inmediatos.

Esta tendencia se profundizó más aún por la naturaleza de las materias primas centroamericanas, simples cosechas agrícolas y dos minerales y por las tecnologías primitivas y poco productivas aplicadas. En realidad, a los primeros pobladores, la agricultura en sentido estricto les pareció una ocupación irrelevante, dado que consideraron como ilimitada la disponibilidad de tierra y de trabajadores. Solamente en las áreas próximas a sus grandes ciudades, donde había un buen mercado para los productos agrícolas europeos o en regiones donde la población nativa había desaparecido rápidamente, por ejemplo, en los alrededores de San Miguel y Trujillo, hubo un temprano interés por poseer tierras.

Los conquistadores que también asumieron el cargo de gobernador también intentaron realizar su ideal político. En efecto, soñaron con establecer una sociedad cuasi feudal, en la cual ellos y sus descendientes se perpetuarían como una aristocracia militar dominante y hereditaria, y como buenos vasallos del rey de Castilla, tendrían el deber de gobernar, defender y mantener la paz en sus respectivos territorios. Este ideal, expuesto y hasta razonado por algunos tratadistas, jamás lo alcanzaron. Los conquistadores estaban mirando al pasado para organizar el futuro, cuando la corona llevaba ya más de treinta años tratando de establecer un Estado centralizado y, en consecuencia, estaba luchando contra el poder político de la nobleza. Por lo tanto, no iba a tolerar la aparición de una nueva aristocracia señorial con ribetes feudales la cual, si llegaba a afirmarse, no habría modo de controlar desde el otro lado del Atlántico.

\section{La evidencia histórica muestra que los indígenas fueron dominados y explotados económica, social y políticamente; pero, pese a ello, no fueron conquistados ideológica ni culturalmente.}


Entre las recompensas que por merced del rey se otorgaron a los conquistadores al asentarse en la tierras ya pacificadas, ninguna fue considerada mayor ni más valiosa que un título de nobleza de Castilla, acompañado de la concesión de extensas tierras en señorío, con sus habitantes como servidores. Asimilando, la conquista a la antigua reconquista y la evangelización a la antigua cruzada, los conquistadores creyeron merecer la misma recompensa que los guerreros medievales obtuvieron luchando en la frontera musulmana. Sin embargo, la nobleza castellana no los aceptó como de los suyos. Más aún, resistió la promoción de los conquistadores a sus filas.

La noblcza castcllana se aprovechó de las gratves denuncias sobre las crucldades de los primeros años de la colonización de Las Antillas hechas por los dominicos y de las disquisiciones legales y éticas de los tcólogos y juristas en la llamada controversia de Indias para rechazar las pretensiones de los conquistadores. Sin embargo, tuvo que reconocer su heroísmo y, por lo tanto, un puñado de conquistadores, cuyas labulosas hazañas no había modo de ignorar o minimizar, consiguicron oblener los apetecidos títulos nobiliarios y los scñoríos. Pese a ello, en opinión de los nobles, quienes, con raras excepciones, no participaron en la conquista, los conquistadores eran pretenciosos advencdizos con las manos teñidas con la sangre de los inocentes indigenas y con riquezas cuyo origen cra al menos sospechoso.

Un grupo ya más numerosos fue recompensado con nombramientos en la burocracia real $y$, de esta manera, ejcrcicron sus cargos en aquellos territorios que ellos mismos habían conquistado. El más apetecido y prominentc fue el de gobernador, lo que, en tcoría, implicaba una delegación limitada del poder político del monarca en un determinado territorio, revocable sin previo aviso y al arbitrio de su voluntad soberana. En la práclica, algunos de esos gobernadores conquistadores fueron exonerados más pronto que tarde del cargo, pero a la mayoría no se le pudo privar de la recompensa mientras vivió y reinó en sus antiguas conquistas como dueños y señores, en beneficio propio y de sus familias y antiguos compañeros de armas, el tiempo suficiente para construir su propio mundo y dejar una huella duradera en la sociedad colonial.

La explotación de los recursos naturales centroamericanos se llevó a cabo a través de la encomienda y la esclavitud ilegal de la población, contra lo cual lucharon proféticamente las primeras generaciones de misioneros y de obispos hasta 1620. Los obispos añadieron a los títulos que definían sus funciones episcopales el de protector de los indígenas. Uno de ellos cuenta que los colonizadores se quejaban porque más parecía obispo de indios que de españoles.

De la controversia de Indias salieron las llamadas Leyes nuevas, promulgadas en 1542 . Estas leyes declararon a la población libre, con el derecho para trabajar por un salario libremente. Pero las presiones de los colonizadores llevaron a que la corona obligara a la población ya reducida en los llamados pucblos de indios a trabajar por un salario fijo y muy bajo. En 1661, los indígenas de Ahuachapán, en memorial dramático, denunciaron que "con todo aqueste trabajo, los que van a las labores no se les paga su trabajo, porque les dan tan grandes tareas que la que es de un día apenas

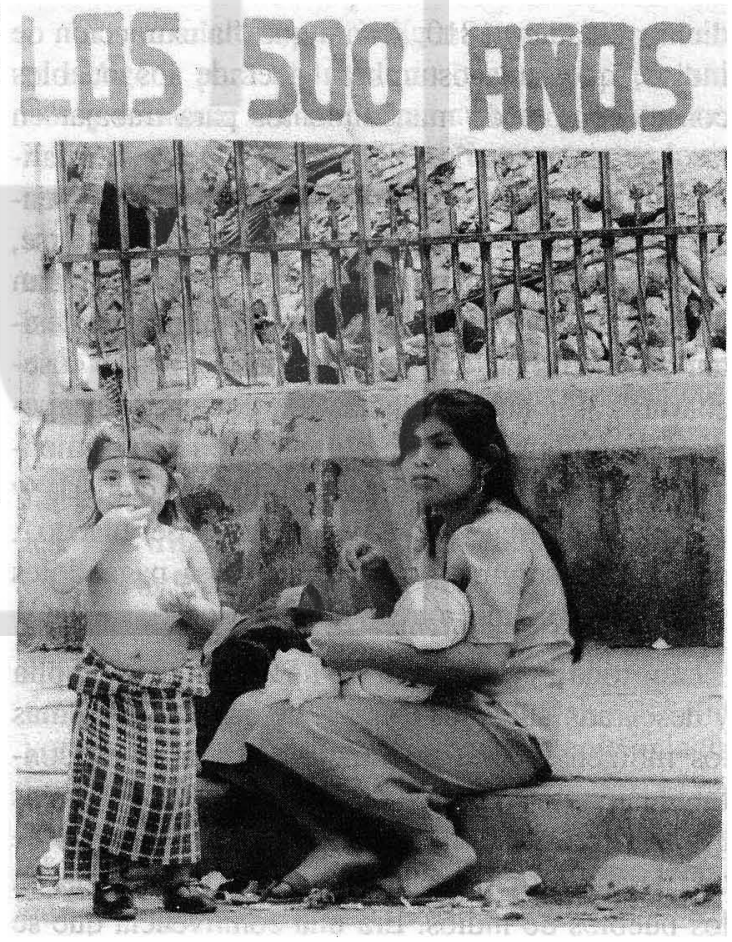


la pueden sacar en toda la semana, y al fin de ella les dan un real o real y medio con nombres (pretextos) que no hicieron más que una tarea".

El obispo Cortés y Larraz, en su Descripción geográfico-moral de la diócesis de Goathemala (1768-1770), después de visitar 427 pueblos y 824 haciendas y refiriéndose a éstas en general y a los desórdenes y a las miserias que encontró en ellas a finales del siglo XVIII, escribe, "si las haciendas fueran una u otra, pudiera tolerarse el daño, solicitando el remedio con silencio; pero siendo tantas ¿quién no clama hasta que se oigan los desórdenes en todo el mundo, para que contribuyan a su remedio...?". Por lo tanto, la existencia del trabajo forzado de la población indígena por un reducidísimo salario era general. Pero eso no era todo, esta forma de trabajo forzado era ejercida violentamente, "estos repartimientos", continúa el obispo de Guatemala, "se hacen con toda violencia, que no se deja de respetar solamente los campos y tierras de los miserables indios, pero ni su salud y vida".

Apenas una década antes de la independencia, los Apuntamientos del Real Consulado sobre la agricultura y comercio del Reyno de Guatemala, un documento elaborado por los comerciantes de dicha ciudad en 1810, señala que "la extracción de indios, que se acostumbra hacer de los pueblos con el nombre de mandamientos para trabajar en las haciendas de los blancos, perjudicará infaliblemente la labranza de los mismos indios teniendo éstos campos propios a que atender y ocuparse, siendo precisamente el tiempo en que se efectúan dichas extracciones el oportuno que ellos necesitan para cultivar lambién sus posesiones o cosecharlas". En consecuencia, los comerciantes pedían no obligar "a indio alguno que tenga sementera propia, o que esté por sembrarla, cuidarla y cosecharla, a que vaya a beneficiar la del blanco... en caso de servirse de los indios, sea pagándoles su trabajo y ocupación sin apremiarlos".

En toda la colonia hubo una tolerancia amplia y descarada antes los ultrajes de que eran víctimas los indígenas. Esta tolerancia era como una confabulación, una especie de solidaridad de todos los grupos libres, incluidos los indígenas liberados de los pueblos, frente a la población aprisionada en los pueblos de indios. Era una connivencia que se extendía desde el presidente y los oidores de la audiencia hasta los alcaldes indígenas. En ella participaban también los ladinos y los negros libres y los esclavos de confianza contaban con ella. Era una coincidencia por encima de todas las contradicciones de la población no indígena. Había consenso sobre el trato que era preciso dar a los indígenas, un trato que presuntamente se "merecían" y sin el cual en seguida surgían "la insolencia" y el alboroto.

Los constantes ultrajes, la crueldad excesiva con la que eran castigados por motivos fútiles y el trato humillante $y$ ofensivo en todo momento eran un recurso para mantener a la población indígena, que era mayoritaria, atemorizada y convencida de que la menor rebeldía sería castigada en forma desmesurada e inmediata no sólo por la autoridad local o colonial, sino por muchos otros, quienes gozaban de impunidad para golpear y se sentían obligados, además, a vigilarla de cerca.

De los azotes y las picotas dan abundante noticia los documentos coloniales, desde puntos de vista muy diversos. El cronista Fuentes y Guzmán, quien fue corregidor en dos ocasiones, cuenta las veces que ordenó azotar indígenas y lo justifica diciendo que "es perder el tiempo con los indios si no les hablan en su modo, y ven que quien les habla es hombre como ellos, y tiene la facultad de empuñar el azote, en que es necesario que se ejercite... porque es una generación (los indígenas en general) que necesita estar debajo del yugo y que no conozcan otra cosa que superioridad y dominio". El texto subraya la necesidad de dominar por el terror.

Hacia 1720, Francisco Ximénez describió la situación de los indígenas en estas breves líneas, "se ven tan avasallados y sojuzgados, que son siervos de los mismos siervos, pues no hay hombre por vil que sea, aunque sea un esclavo, que no los ultraje y maltrate, que es indecible la servidumbre en que se ven". Medio siglo más tarde, el obispo Cortés y Larraz formuló en pocas palabras la confabulación del terror en toda su crudeza, "lo cierto es que los miserables a la voz de cualquiera luego están amarrados a la picota, hombres, mujeres, chicos y grandes... pues se azotan muchas veces con sobrada crueldad, y muchas sin motivo alguno, y mu- 
chísimas y cuasi siempre por lo que no se azotaria si no fuera indio... los motivos para azotarlos son por cualquier cosa que no salga a gusto de los otros. De la crueldad no produzco otros documentos sino que con bastante frecuencia oigo sus clamores y llantos desde mi cuarto o aposento, y aun los latigazos de bastante lejos". Aquí el obispo no se está refiriendo a un pueblo lejano, en el altiplano o en El Salvador, sino a la capital del reino. Era tan insoportable el sufrimiento que al obispo se le ocurrió la posibilidad que los indígenas llegaran a sublevarse y se negaran a dar de comer a los habitantes de la ciudad.

El obispo hizo otra observación muy reveladora del terror en el cual vivía la población. Cortéz y Larraz cayó en la cuenta que los indígenas nunca contestaban con una aserción a sus preguntas, sino que siempre respondían con un "quién sabe", "tal vez", "bien puede ser" - el "a saber" tan común entre nosotros. Entonces quiso averiguar la causa de este hábito tan extraño. Comprobó que contestaban de esta manera no sólo cuando se les interrogaba sobre asuntos de cierta importancia, sino que también al preguntarles si los caminos estaban en buen estado, si el pueblo más próximo aún estaba lejano o si el río estaba crecido. "Para asegurarme de cosa tan extraña como increíble", continúa el obispo, "me ha sucedido llevar conversación con algunos indios en el idioma castellano, y decirle a alguno: ¿parece que sabes castilla? y responderme: sí mi padre; levantar un poco la voz y decirle con alguna seriedad, ¿con que sabes castilla? y responder: no mi padre. Alguna vez he preguntado también: ¿ya has comido? y responderme: sí mi padre. Levantar un poco la voz: ¿con que ya has comido? y responderme: no mi padre. De todo lo cual se infiere que los miserables miran con mucha indiferencia el decir sí o no a cuanto se les pregunta... y que su objeto único es el evitar el castigo sin ponerse en otro cuidado... viven tan acobardados y temerosos que lo que que procuran en sus respuestas no es la verdad, sino el que sean a gusto de quien pregunta".

El terror no fue suficiente, sin embargo, para evitar los motines, que fueron una realidad cotidiana en la sociedad colonial. La documentación se refiere a ellos con frecuencia y los cronistas los mencionan en muchos puntos de sus relatos. La abundancia de la documentación y de las referencias indica que hubo motines de manera intermitente y dispersa, desde el fin de la fase militar de la conquista hasta después de la independencia.

La raíz de los motines era el sistema colonial mismo, puesto que fueron reacciones violentas contra la explotación legal y contra las exacciones y los abusos. La corona toleró los negocios ilegales de los miembros de la audiencia, siempre que éstos cumplieran fielmente con la recaudación del tributo. Los miembros de la audiencia toleraban los abusos y los negocios brutales de los corregidores y los alcaldes mayores siempre que éstos les dieran alguna comisión y garantizaran la recaudación del tributo que ellos debían enviar a la corona. Los corregidores dieron mano libre a algunos indigenas en los pueblos, siempre que recaudaran el tributo y se avinieran a participar y colaborar en sus negocios ilegales. Era una enorme trama de abusos consabidos y tolerados, lo que significaba que cualquiera podía arrancar algo a los indígenas, siempre y cuando cumpliera con las obligaciones de la autoridad inmediata superior y obtuviera lo que correspondia al rey.

El verdadero motín indígena era un movimiento indígena para liberarse de la dominación exterior y restaurar así su propia cultura y su autonomía. Eran movimientos nativistas, orientados a servir y perpetuar ciertos aspectos de la cultura tradicional. Los motines se produjeron en momentos de gran presión externa provocada por el cobro excesivamente riguroso del tributo y por la aplicación de nuevas presiones para erradicar la cultura y la religión prehispánicas.

El cobro excesivamente riguroso del tributo fue la razón más frecuente de los motines coloniales. Los tributarios se quejaron constantemente de que se morían de hambre por las presiones que sufrian al pagarlo. Frecuentemente, por causa de epidemias y hambre, la población disminuía y, por descuido de los corregidores o de los alcaldes mayores, la lista de tributarios se mantenía intacta. Entonces, para pagar por los muertos, "los próximos" y "los reservados", es decir, los menores de dieciocho años y los mayores de cincuenta, tenían que trabajar para tributar. En algún caso, "los 


\section{Toda expansión imperial es igualmente devastadora para los pueblos sometidos y sojuzgados, pues las aventuras imperiales siempre han estado impulsadas por el afán de enriquecimiento.}

próximos" apenas tenían trece años. Después de pasar por momentos de mucha presión, los pueblos pedían un nuevo censo y una nueva tasación del tributo. En estos casos, los corregidores no aceptaban fácilmente elaborar un nuevo censo, porque la recaudación del tributo disminuiría. Desesperados, los indígenas se rebelaban. Pero también ocurió lo contrario. En los pueblos donde la población aumentaba, sus habitantes se las arreglaban para demorar el ajuste de la lista de tributarios. En estos casos, el intento del corregidor para elevar el tributo fue motivo de alborotos y tumultos. Mencionar la elaboración de un censo y de una nueva lista de tributarios, era motivo de rebeldia en los pueblos.

Además, los recaudadores del tributo estaban muy interesados en cobrar más de la cantidad establecida por el censo, porque el excedente se lo quedaban fraudulentamente. Uno de los mecanismos utilizados fue forzar a tributar a jóvenes menores de dieciocho años, quienes aún no estaban inscritos en la lista de tributarios. Para ello, los obligaban a casarse y luego alegaban que la ley establecía que los menores de dieciocho años que estuvieran casados debían tributar.

La segunda causa de los motines coloniales fue el rechazo a nuevas presiones para erradicar la cultura y la religión prehispánica de los pueblos de indios. Thomas Gage registró en su crónica un incidente bien conocido en Guatemala y del que él mismo fue protagonista. Durante su visita al pueblo de Mixco, intentó destruir un ídolo frente al cual se hacían secretamente ritos prehispánicos. Todo el pueblo se levantó y Gage fue atacado personalmente. El levantamiento fue controlado con los caballos y las armas de los hacendados de los alrededores.

Los colonizadores eran muy conscientes de que la religión prehispánica aún estaba viva y que, en la medida en que los indígenas se mantuvieran apegados a ella, su conquista no sería completa. Más aún, en los motines siempre salía a relucir, en una u otra forma, esta religión antigua. Fuentes y Guzmán cuenta alarmado que "cada día se desenlierran y sacan de los surcos de los sembrados, figuras de feísimas y desproporcionadas representaciones de hombres y mujeres, de sierpes, de monos, de águilas y otras infinitas y ridículas figuras... que ruedan de unas partes a otras". Para el cronista, las figuras que aparecían eran detestables y despreciables, porque simbolizaban la presencia de una religión pagana y sobre todo la resistencia a la conquista cultural.

La religión prehispánica estaba viva gracias a la resistencia de los indígenas. Para los representantes del sistema colonial, esta resistencia era rebeldía y barbarie, cuando no era interpretada como cosa del demonio, que debía ser suprimida a como diera lugar. Si la población mantenia sus creencias, dioses y cultos prehispánicos, el cristianismo había fracasado, es decir, la población no se había convertido a la fe del invasor. $Y$ no estamos hablando del comienzo de la colonia, sino de su final.

En efecto, Cortés y Larraz, después de haber visitado toda su diócesis, estaba convencido de que el cristianismo de los indigenas era superficial. El adorno de los templos y lo que gastaban en ellos no era indicio de cristianismo serio para el obispo. En la visita de la parroquia de Santo Tomás Texacuangos escribió, "aunque algunos se persuaden de hallarse bien fundada la religión cristiana en los indios por lo que gastan en los templos y ornamentos, este es un argumento muy equivoco, supuesto que se sirven de los mismos para su idolatría", lo que corroboró en la parroquia de San Marcos, donde encontró una iglesia hermosa que "no cesan de adornarla", pero todo lo usaban "para servirse de ello para sus idolatrías... son tan astutos en el particular de ocultar su idolatría, que no hay arte que no inventen para ello hasta poner los ídolos escondidos en las imágenes; por otra parte tienen tanto miedo los pobres curas, de que si se empeñan en descubrirlos, les quitaran la 
vida". En Caluco, encontró el mismo temor en el párroco y la misma determinación de los indígenas, "pero en tocándoles puntos de idolatría, son capaces de cualquier atentado para no ser descubiertos".

Volviendo al tema de la evangelización, Cortés y Larraz era de la opinión que "tienen tan arraigadas estas supersticiones que no hay modo para persuadirlos de lo contrario, y es sin duda porque el demonio en estas cosas les dispone los sucesos correspondientes... hasta hoy sus ministros y curas más celosos no han podido conducirlos por el camino seguro de la fe".

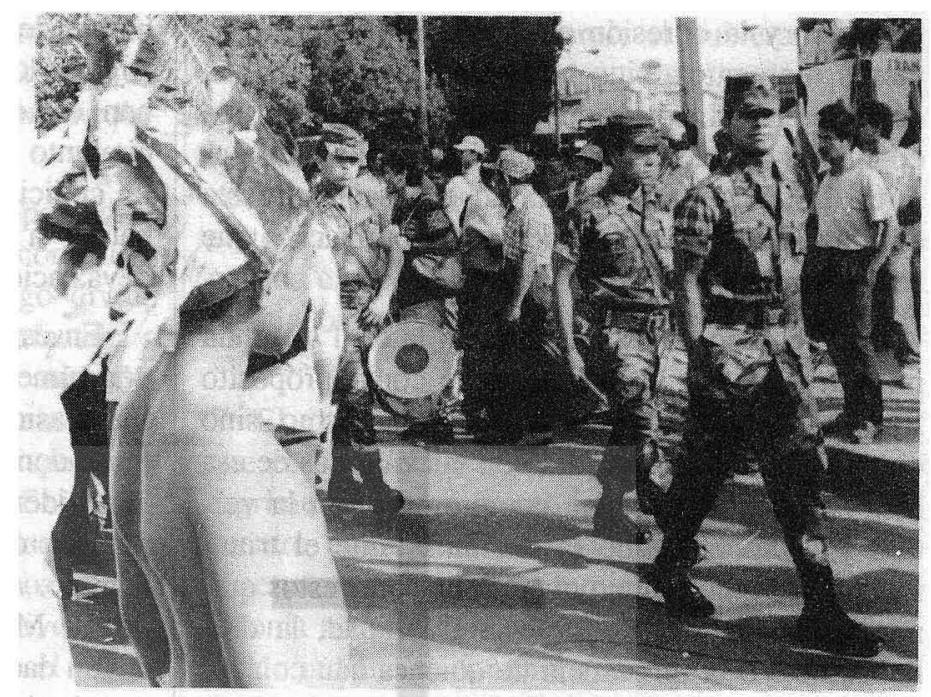

En la parroquia de Izalco, el obispo encontró que sus habitantes no aprendían la doctrina ni asistían a misa, por "una especie de repugnancia positiva y tal, que se esconden en los bosques, que los padres ocultan a los hijos, que cuantos pueden se resisten y que los que no se pueden resistir y son llevados a la iglesia es preciso cerrar las puertas, para que no se salgan". El obispo fue más allá con la siguiente observación, “...tienen a los españoles y ladinos por forasteros y usurpadores de estos dominios, por cuyo motivo los miran con odio implacable y en lo que los obedecen es por puro micdo y servilismo. Ellos no quieren cosa alguna de los españoles, ni la religión, ni la doctrina, ni las costumbres".

Francisco Ximénez comprobó que las creencias y tradiciones del Popol Vuh, descubierto por él, perduraban, "hallé que era la Doctrina que primero mamaban con la leche y que todos ellos casi la tienen de memoria". Cortez y Larraz era de la misma opinión, "es tanta la desconfianza que de los españoles tienen, que porque los ministros (curas) son españoles casi se puede decir que no creen lo que les dicem, poniéndolo siempre en duda...".

En conclusión, la sociedad colonial no fue pacífica, como algunos se empeñan en hacer creer. Fue una sociedad violenta, plagada de abusos, ilegalidades y fraudes. La evidencia histórica mues-

tra que los indígenas fueron dominados y explotados económica, social y políticamente; pero, pese a ello, no fueron conquistados ideológica ni culturalmente. Resistieron hasta la rebelión abierta todo intento de conquista ideológica. La sociedad colonial centroamericana no fue ni mejor ni peor que otras sociedades que padecieron una situación similar. Ante la evidencia histórica, lo que no se puede sostener bajo ningún punto de vista es que haya sido una sociedad donde se encontraron dos culturas y dos pueblos pacíficamente.

\section{El imperialismo es intrínsecamente devas- tador}

Este breve recorrido por la la evidencia documental más autorizada de Centroamérica proporciona una idea general, pero suficientemente clara, sobre lo que fue en realidad el descubrimiento, la conquista y la colonia. A propósito he dejado de lado la documentación generada alrededor de la controversia de Indias y por los primeros obispos, la cual, con frecuencia, es descalificada por considerarla una de las fuentes de la llamada leyenda negra. No hace falta recurrir a estos documentos para aproximarse a la dramática realidad histórica del descubrimiento y la conquista. En las crónicas oficiales hay abundante evidencia de esa realidad.

La explotación y la dominación no se limitaron al descubrimiento y a la conquista. La sociedad colonial les dio continuidad, demostrando que la 
injusticia y la opresión no se limitaron a los primeros momentos, sino que se institucionalizaron en la sociedad posterior. El descubrimiento y la conquista desataron los dinamismos que configuraron la sociedad colonial. En ella se manifiesta durante siglos la explotación y la dominación que se han querido negar.

El recuerdo de esta historia en la cual se funda nuestra sociedad actual, no tiene como propósito fomentar la leyenda negra ni el masoquismo, sino que es una obligación para con las víctimas de esa historia y es también un compromiso con la verdad y la honradez de la realidad. Ante el triunfalismo de quienes han querido celebrar estos quinientos años y ante la irresponsabilidad, la deshonestidad o la ignorancia de quienes han colaborado con ellos proporcionándoles datos históricos tergiversados o interpretaciones abstractas e idealistas, ajenas a la dura realidad histórica, es necesario volver a la historia para denunciar la falsedad de sus celebraciones y para desenmascarar sus fantásticas interpretaciones históricas. No hacerlo, concediéndoles continuar adelante con sus mentiras históricas, es favorecer la impunidad.

La hisloria de la humanidad muestra que no se trata de buscar en España un culpable ni de pedirle cuentas anacrónicamente. Se trata de denunciar que no se puede celebrar festivamente lo que fue la destrucción de pueblos enteros y el sometimiento de los sobrevivientes durante los largos siglos coloniales. Ninguna de estas realidades puede ser celebrada sin ofender a las víctimas de ayer y de hoy, pues los descendientes de aquellos pueblos siguen siendo explotados y dominados, están marginados y son considerados ciudadanos de segunda calegoría, cuando no son sometidos a campañas de exterminio físico.

En el siglo XVI, España llegó a convertirse en el imperio más grande del mundo occidental. Parte de esa expansión imperial fueron el descubrimiento, la conquista y la colonia. Si no hubiesen venido los castellanos, hubieran venido los portugueses o los ingleses o los holandeses y la historia de Centroamérica hubiera sido más o menos similar. Cualquiera de las potencias nacientes de la Europa de entonces pudo haber descubierto y conquistado Centroamérica. Toda expansión imperial es igual- mente devastadora para los pueblos sometidos y sojuzgados, pues las aventuras imperiales siempre han estado impulsadas por el afán de enriquecimiento de los conquistadores y colonizadores. La codicia lleva al saqueo, a la crueldad, al asesinato y a la mentira para encubrir la muerte y la devastación dejadas por el imperialismo.

En este sentido, conviene recordar que el mayor número de víctimas mortales prehispánicas no fue ocasionado por las acciones bélicas de los conquistadores ni por la dominación colonial, sino por las epidemias. Las mortandades anteriores a 1492 parecen estar relacionadas con malas cosechas y hambre. Aunque las zonas más densamente pobladas de México central y Perú, desde hacía siglos, tenían dadas las condiciones para desatar las cadenas de transmisión de las enfermedades infecciosas, éstas no se produjeron. Probablemente, estas enfermedades no aparecieron por la ausencia de animales domésticos de costumbres acusadamente gregarias.

La primera epidemia de viruela llegó en 1518 a La Española y, prácticamente, extinguió a toda la población sobreviviente, la cual acababa de ser agrupada en poblados. La epidemia pasó a México e hizo grandes estragos entre los aztecas durante la conquista. Cuando los conquistadores fueron expulsados de Tenochtitlán, sus enemigos victoriosos no los persiguieron y aniquilaron antes de que pudieran rehacerse, porque la viruela acabó con el jefe azteca y con muchos de sus guerreros. En 1520 , la viruela llegó a Guatemala y cinco años más tarde, se difundió por el norte del incario, originando la muerte del inca $\mathrm{y}$, como consecuencia, la guerra civil que facilitó la conquista de Pizarro. La viruela mató a un tercio de la población nativa en el teatro de la conquista. En El Salvador, según los cálculos más rigurosos y donde, en 1519 , la población oscilaba entre las 700 y 800 mil personas, ésta se había reducido a 400 ó 500 mil personas cuando Alvarado llegó.

Después de la viruela se difundió el sarampión, en 1530-1540. Otra enfermedad que bien pudo ser el tifus, empezó a causar estragos en 1546 y duró hasta 1548. En 1558 apareció una gripe maligna. Por si esto fuera poco, en Perú, los rebaños de llamas sufrieron una mortífera epizootia en 1544- 
1545. A esto hay que añadir las epidemias locales, que azotaron Centroamérica con violencia en un momento u otro de la conquista y durante la colonia.

Tanto los conquistadores como la población interpretaron la enfermedad epidémica como una forma inequívoca y horrorosa de castigo divino que se cebaba en aquélla, pero que no afectaba a los primeros. Los misioneros quedaron anonadados ante esta inexplicable forma de justicia divina que aniquilaba a los buenos nativos y respetaba a los conquistadores codiciosos y crueles. El impacto de las epidemias desmoralizó a la población que perdió la voluntad para vivir, hubo casos de inlanticidio "piadoso" y de suicidios colectivos e individuales. Quizás ello explique en parte el carácter taciturno y la "pereza" que muchos documentos atribuyen a los sobrevivientes. En vista de la parcialidad divina a favor de los invasores, a los sobrevivientes sólo les quedó aceptar la superioridad de aquéllos, puesto que sus dioses habían muerto y, por lo tanto, los habían abandonado.

La mortandad causada por las epidemias y el hundimiento psicológico de la población sobreviviente se hubieran dado independientemente de la nacionalidad de los curopeos que hubiesen llegado. La catástrofe demográlica de la conquista y de los primeros años coloniales es un resultado directo de la expansión imperialista de España. Las injusticias y los males que se siguieron obedecen a la naturaleza impcrialista de aquella expansión. De hecho, todos los imperialismos son intrínsecamente explotadores y dominadores, por lo tanto, injustos y violentos, inhumanos y deshumanizadores.

Obviamente, ni la injusticia, ni la violencia, ni la inhumanidad pueden ser celebradas. Es cierto que hubo cosas positivas como la unificación del mundo, el castcllano, la cultura hispana, la religión y el mestizaje; pero ninguno de estos elementos fue pretendido directamente por quienes llevaron a cabo el descubrimiento, la conquista y la colonia, sino que todos ellos se dieron por añadidura y a pesar de. Si bien es cierto que el mundo se unificó, también es cierto que se perdió una oportunidad para establecer un mundo más humano y justo. El castellano es la lengua dominante en la actualidad, porque csa cra la lengua de los des- cubridores y conquistadores; si hubieran venido ingleses, hablariamos inglés. Aunque algo parecido puede decirse respecto a la cultura en general, no debe olvidarse que la mayoría de la población colonial, los indígenas, no se beneficiaron de la cultura española, puesto que la educación les fue negada expresamente, excepto a unos cuantos privilegiados por ser descendientes de los antiguos señores.

El mestizaje amerita un párrafo aparte, puesto que es uno de los logros que con más orgullo se esgrime para demostrar la existencia de un encuentro cultural. En primer lugar, es interesante observar que los que dirigieron la conquista y la colonia no contaron con este fenómeno. La legislación indiana se concentra casi exclusivamente en los blancos y en los indígenas, pero no en los mestizos. El mestizo no está considerado en la legislación. Su presencia en la sociedad fue un subproducto molesto y para el que no había sitio, quizás ello contribuyó a su naturaleza de desarraigado. Los indígenas no lo consideraban uno de los suyos, ni el mestizo quería considerarse indígena, todo lo contrario, por lo que a él tocaba, más quería asimilarse a y ser tenido por blanco; pero éstos, españoles y criollos, lo despreciaban, considerándolo medio indio.

En segundo lugar, en la raíz del mestizaje hay mucha violencia sexual de la cual fue víctima la mujer indígena. El origen del mestizaje se encuentra en las primeras violaciones de las indígenas por parte de los conquistadores; y si no hubo violación, los conquistadores y los primeros pobladores tomaron a las mujeres indigenas y las convirtieron en sus amantes con engaños o por la fuerza. Los españoles y criollos no acostumbraban ofrecer matrimonio a sus mujeres indígenas ni reconocían como suyos a sus hijos mestizos. Las esposas e hijos legítimos eran los blancos. Por otro lado, las uniones siempre fueron de un varón blanco con una mujer indígena, es decir, la mujer blanca nunca tuvo oportunidad para unirse con un indígena varón. Semejante posibilidad era una aberración para los códigos sociales y culturales de la sociedad colonial. Por consiguiente, no se puede dar por obviado el fenómeno del mestizaje.

Los elementos positivos que tiene esta aventu- 
ra imperial estuvieron marcados de forma determinante por la destrucción original y originante. Más aún, por si todavía queda alguna duda sobre esta dolorosa realidad histórica, los primeros pobladores de la colonia estaban tan convencidos de que los indígenas eran animales o semianimales que un misionero dominico tuvo que ir a Roma en 1537 y, prácticamente, forzar a Paulo III a redactar la bula Sublimis Deus, en la cual "por las presentes lelras decretamos y declaramos, con nuestra autoridad apostólica, que los referidos indios y todos los demás pucblos que en el futuro vengan al conocimiento de los cristianos, aunque se encuentren fuera de la fe de Cristo, no deben estar privados ni deben serlo de su liberlad ni del dominio de sus cosas; y más aún, que pueden usar, poscer y gozar libre y lícitamente de esa libería y de ese dominio; y que no deben ser reducidos a esclavitud...".

Un símbolo reciente de la devastación de los imperios es la sede de la nueva embajada de Estados Unidos en San Salvador, la cual ha sido construida sobre las ruinas arqueológicas de lo que fue el reino de Cuzcatlán. Más aún, para construir la embajada destruyeron el sitio arqueológico y lo saquearon. Por razones económicas y políticas, estadounidenses y salvadoreños consideraron más rentable continuar con la construcción de la embajada que conservar las ráíces de la nación.

Así, pues, se perdió la oportunidad para construir una unidad mayor y más fratema. Se perdió una oportunidad para humanizar y para hacer del nucvo mundo un nucvo mundo. 